TAO, Vol. 15, No. 1, 1-13, March 2004

\title{
Investigation of Seismicity in Central Taiwan Using the Accelerating Seismic Energy Release Model
}

\author{
Jeng-Cheng Wang ${ }^{1}$ and Chiou-Fen Shieh ${ }^{1, *}$ \\ (Manuscript received 28 May 2003, in final form 27 October 2003)
}

\begin{abstract}
A time-to-failure method developed from the accelerating seismic energy release model is used to scrutinize the seismicity of central Taiwan for 40 earthquakes with magnitude greater than 4.5. First, mainshocks and their pre-events are identified, and then adopted as observed data set. The nonlinear time-to-failure equation is separated into two linear equations, and then parameters are estimated by using linear least-square twice. The model constructed from the estimated local parameters, is then used to predict time-of-failure and magnitude of mainshocks. Comparing predicted results and 40 mainshocks, the maximum misfits are only 0.98 years in time and 1.2 unit in magnitude, which indicate that accelerating seismic energy release model could be applied in central Taiwan as a useful tool for the study of seismicity.
\end{abstract}

(Key words: Accelerating seismic energy release model, Mainshock, Pre-shock, Time-of-failure, Seismicity)

\section{INTRODUCTION}

Taiwan is located on the collision boundary of the Eurasian and Philippians Sea plates where most earthquakes occur in the eastern subduction zone and western compression fault zone. Since major cities are located in the western Taiwan with very high population, and more than 10 highly-destructive earthquakes have occurred in the past century; the recent $1999 M_{w}$ 7.6 Chi-Chi Taiwan earthquake is the most devastating example, earthquake hazard and prevention is an environmental issue of great importance. The study of precursor is an interesting subject and worth of investigating in this area; thus, seismicity in central Taiwan was studied using accelerating seismic energy release model.

${ }^{1}$ Institute of Seismology and Applied Geophysics, National Chung Cheng University, ChiaYi, Taiwan, ROC

* Corresponding author address. Dr. Chiou-Fen Shieh, Institute of Seismology and Applied Geophysics, Chia-Yi, Taiwan, ROC; E-mail:seifent@eq.ccu.edu.tw 
The accelerating seismic energy release model is based on time-to-failure method, which describes a seismic energy release relationship between pre-events and mainshock by a nonlinear equation. This model was developed from fracture mechanics and crack propagation in the elastic media (Das and Scholz 1981) and was used originally to explain the phenomena of crack growth and pre-shocks. Later on, it was extended to study the earthquake precursor (Varnes 1989; Bufe and Varnes 1993; Bufe et al. 1994). Brehm and Braile $(1998,1999)$ modified this model by proving that two constant ratios, $\mathrm{km}^{-1}$ [see equation (1)], is a function of mainshock, thus reducing four unknowns to three. They used this modified time-to-failure method for the New Madrid and Southern California areas to forecast intermediate-term earthquakes, and found that seismicities in these two areas can be fitted into an accelerating seismic energy release model. The data used in this study is from the earthquake catalogue of Taiwan from 1973 to 1998 in the area of $23^{\circ} \mathrm{N}-24^{\circ} 30^{\prime} \mathrm{N}$ and $120^{\circ} \mathrm{E}-121^{\circ} 20^{\prime} \mathrm{E}$, as shown in Fig. 1.

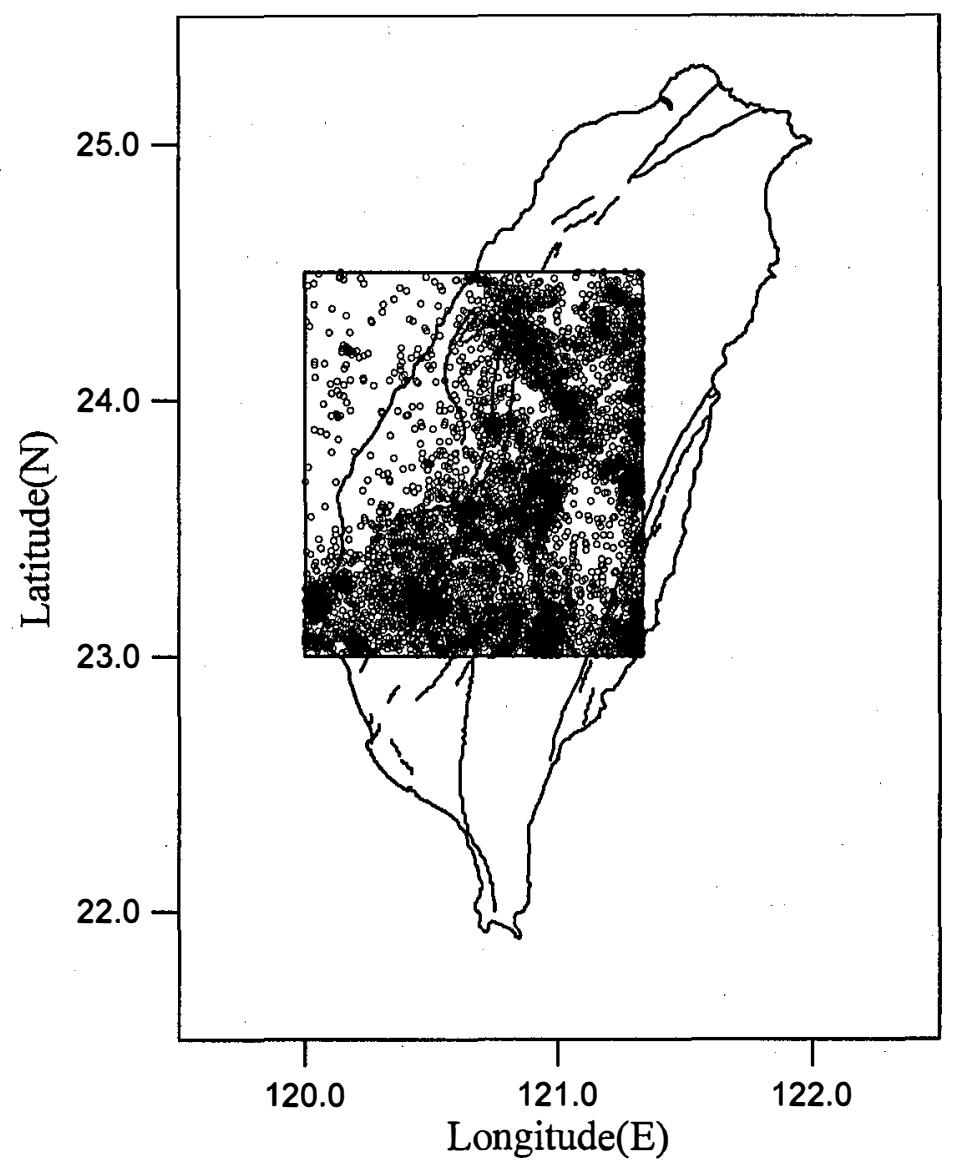

Fig. 1. The studied areas of central Taiwan and their seismicity. 


\section{SELECTION OF MAINSHOCK AND PRE-SHOCKS}

In order to identify mainshocks and their pre-events from the catalogue, some restrictions ought to be clarified. Four rules are used to opt for mainshock, those are: 1 . There are at least 10 minimum pre-events whose magnitude must greater than magnitude completeness $\left(M_{c}\right) 2$. More than 6 years of pre-shocks data is needed, thus, mainshock should be searching since 1979, 3. Disturbing events do not exit, which means that there are no earthquakes with $M \geq 4.5$ occurring three days before mainshock (Brehm and Braile 1999), and 4. Mainshock should not be an aftershock of a large event, thus, declustering after larger event is needed in advance. The sorted mainshocks in central Taiwan that satisfy above regulations are displayed in Table-1, where the 6 largest mainshocks are marked in alphabetic order from a to f for later discussional examples. The magnitude completeness is determined from the distribution of magnitudefrequency, as shown in Fig. 2 for Central Taiwan, where the minimum magnitude that satisfies the linear part is chosen. Using Z-map software (Wiemer 2001), $M_{c}=2.4$ is determined for central Taiwan; therefore, only earthquakes with magnitude greater than 2.4 in the catalogue are used.

To search for pre-shocks for each mainshock, a proper radius, $\mathrm{R}$, which is defined by the distance between mainshock of magnitude $M_{i}$ and the nearest pre-shock with magnitude greater

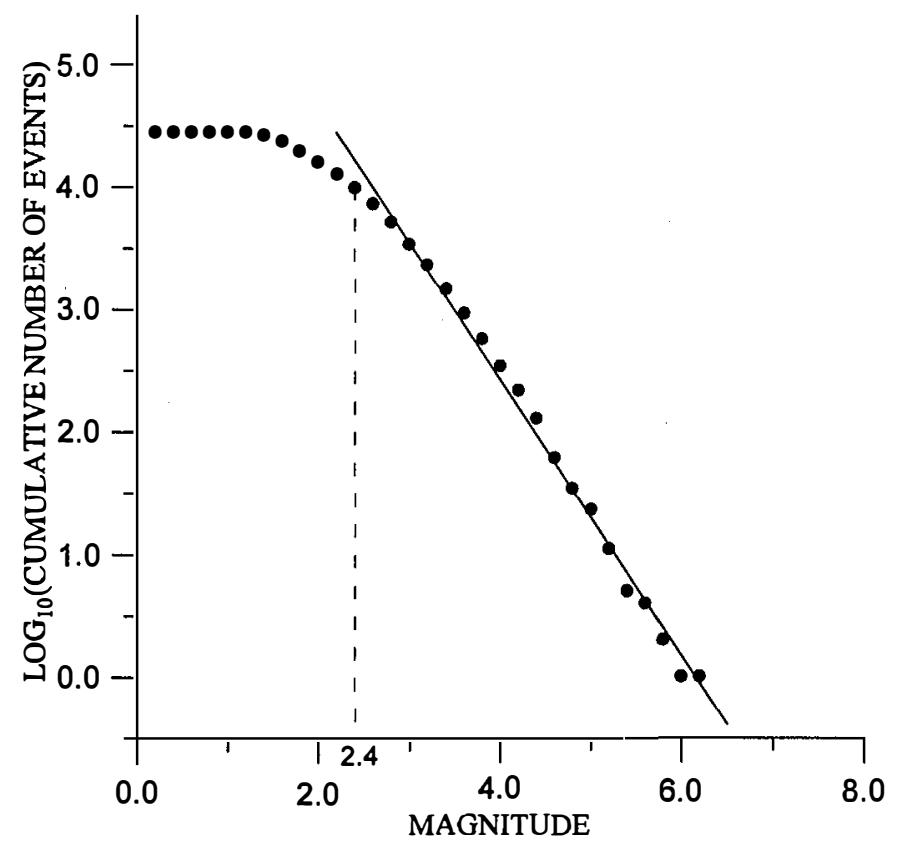

Fig. 2. The Gutenber-Richter magnitude-frequency relationship for central Taiwan. The magnitude completeness, $M_{c}$, is estimated from the linear part of the curve, and $M_{c}=2.4$ is obtained by performing Z-map software. 
than $M_{i}-0.5$, has to be determined. The proper radius is related to the magnitude of mainshock with relationship of $\log \mathrm{R} \propto 0.36 M_{i}$ (Jaume and Sykes 1999). The variation of $\mathrm{R}$ for chosen mainshocks in Central Taiwan lies in $2.2 \mathrm{~km}$ to $57.9 \mathrm{~km}$. Earthquakes with $M \geq M_{i}-2$ located in a circle of radius $\mathrm{R}$, with center in the hypocenter of mainshock, are classified as pre-events, and at least 10 of them are necessary for each chosen mainshock. The pre-shock sequences for the 6 largest mainshocks, marked with triangles, are selected based on above the mentioned regulations and are shown in Fig. 3.

(a)

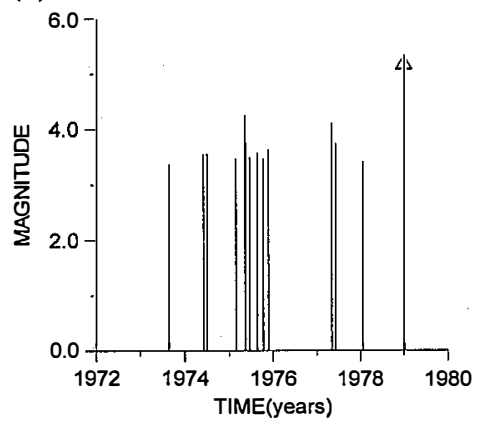

(c)

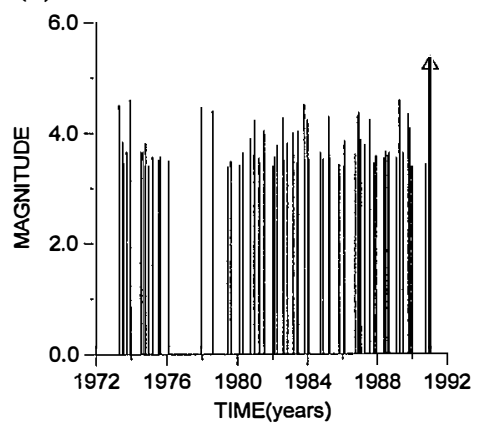

(e)

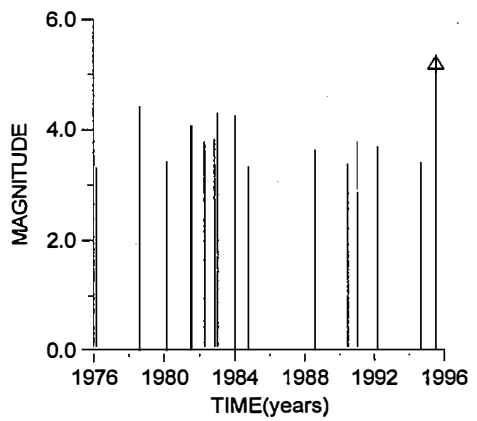

(b)

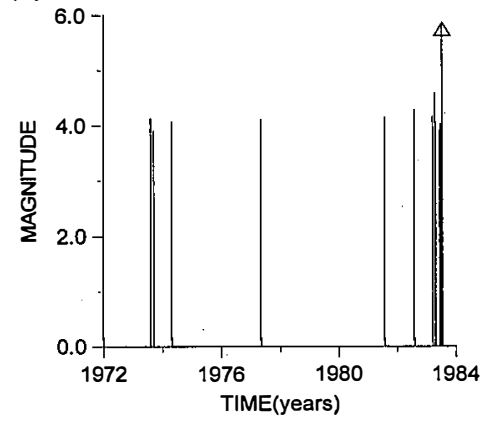

(d)

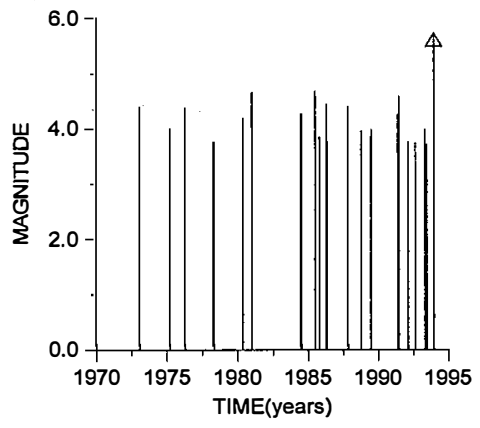

(f)

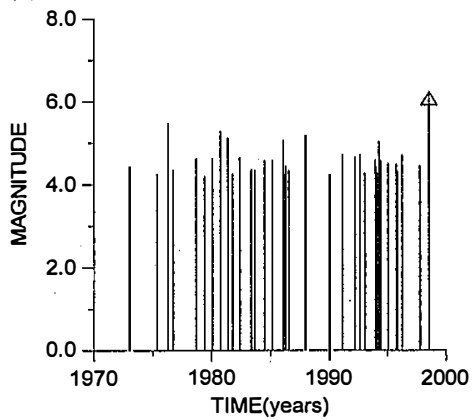

Fig. 3. Pre-shock sequences of 6 largest mainshocks marked with alphabetic letters from a to fin Table-1. The mainshocks are marked with triangular. 


\section{METHOD}

The time-to-failure equation developed from fracture mechanism and crack propagation was rearranged (Bufe and Varnes 1993) and modified (Brehm and Braile 1999) as follows:

$$
\sum \sqrt{E}=\left(K_{p e}+K_{m s}\right)-[k / m]\left(t_{f}-t\right)^{m}
$$

where $\sum \sqrt{E}$ is cumulated square root of earthquake energy in a selected area; $K_{p e}$ is cumulated square root of pre-event energy; $K_{m s}$ is square root of mainshock energy; $t_{f}$ represents time-of-failure of predicted earthquake, and $m, k$ are constants.

The energy in equation (1) is transformed from magnitude by first converting local magnitude $\left(M_{L}\right)$ into seismic moment $\left(M_{0}\right)$ by (Wang 1992)

$$
\log M_{0}=14.571+1.598 M_{L}
$$

And then $M_{0}(\mathrm{~N}-\mathrm{m})$ is converted into energy $E(\mathrm{~N}-\mathrm{m})$ by (Kanamori 1977)

$$
M_{0}=20000 E .
$$

The main principle of the modified time-to-failure method is to reduce the number of unknowns by searching for a relationship between $\mathrm{km}^{-1}$ and $M_{0}$. Brehm and Braile (1999) combined the characteristic of fault mechanic (Varnes 1989) and the relationship between seismic moment and fault length (Kanamori and Anderson 1975) to derive an equation as follows,

$$
\log _{10}(k / m)=\mathrm{A} \log _{10}\left(M_{0}\right)+\mathrm{B}
$$

where $\mathrm{A}, \mathrm{B}$ are unknown constants.

The meaning of equation (4) is that $\mathrm{km}^{-1}$ is a function of the magnitude of the mainshock; thus, A and B need to be determined in advance for a specific area.

First, 71 earthquakes with $M_{L} \geq 4.5$ from 1979 to 1998 in central Taiwan are picked, but only 40 of them satisfy the condition mentioned above as mainshocks, and are listed in Table-1. Second, the proper radius and pre-events of each mainshock are classified. Assume that there are $\mathrm{N}$ pre-events for each mainshock, then rearrange equation (1) into following form for the former $\mathrm{i}$-th pre-events, and $\mathrm{i}=1 \sim \mathrm{N}$

$$
\log _{10}\left(K_{p e}+K_{m s}-\sum_{j=1}^{i} \sqrt{E_{j}}\right)_{i}=\log _{10}(k / m)+m \log _{10}\left(t_{f}-t_{i}\right)
$$


or in a simple linear form

$$
y=p+q x
$$

where $\mathrm{p}=\log _{10}(k / m), \mathrm{q}=m, \mathrm{x}=\log _{10}\left(t_{f}-t_{i}\right), \mathrm{y}=\log _{10}\left(K_{p e}+K_{m s}-\sum_{j=1}^{i} \sqrt{E_{j}}\right)_{i}$.

Since $\mathrm{x}$ and $\mathrm{y}$ can be determined from mainshock and pre-events, $\mathrm{N}$ set of data $\left(\mathrm{x}_{\mathrm{i}}, \mathrm{y}_{\mathrm{i}}\right)$ can be calculated. Thus, the values of $\mathrm{p}$ and $\mathrm{q}$ for each mainshock can be estimated by the linear least-square method. The circles in Fig. 4 display the estimated value of $\log _{10}(\mathrm{k} / \mathrm{m})$ (i.e. p-value) versa $\log _{10} M_{0}$ for all 40 mainshocks. Using these results, the constants A and B in equation (4) can be estimated, again, using the linear least-square method, as the linear part shown in Fig. 4 where, $A=0.4964, B=-1.9491$ are determined for central Taiwan. Substituting the values of $\mathrm{A}$ and $\mathrm{B}$ into equation (4), the model that is suitable for central Taiwan can be rewritten as follow

$$
\log _{10}(k / m)=0.4964 \log _{10}\left(M_{0}\right)-1.9491
$$

or

$$
f\left(K_{m s}\right)=k l m=10^{\left[0.4964 \log _{10}\left(M_{0}\right)-1.9491\right]} .
$$

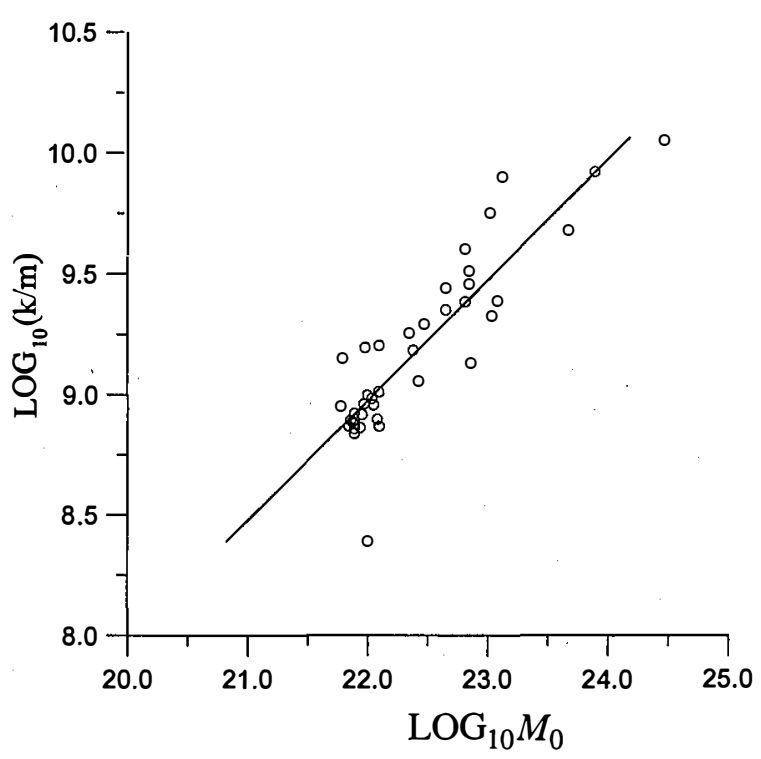

Fig. 4. The $\log _{10}(\mathrm{k} / \mathrm{m})$ of each mainshock $\left(\log _{10} M_{0}\right)$ estimated from equation (5) is marked by a circle, whereas, the relationship in equation (4), therefore, can be found through linear least-square method. $\mathrm{A}=0.4964$, $B=-1.9491$ in equation (4) are then determined. 
Rewrite equation (1) as

$$
\sum \sqrt{E}=\left(K_{p e}+K_{m s}\right)-f\left(K_{m s}\right)\left(t_{f}-t\right)^{m}
$$

Substituting equation (8) into (9), the accelerating seismic energy release model of central Taiwan is determined.

\section{DATA ANALYSIS}

To predict time-of-failure and magnitude of mainshock from the constructed model of equation (9), the procedure is first taking the time of the last pre-event plus 0.02 years as a starting time, and then covering up the next four years as a predicting time-range. Secondly, the predicted earthquake magnitude lies in 4.5 to 7.0. The time-range (four years) and magnitude-range (4.5 - 7.0) are arranged as horizontal and vertical axes, respectively, with 0.01 as increment in time and magnitude. Thus, there are many grids, each corresponding to an assumed time-of-failure $\left(t_{f}\right)$ and mainshock energy $\left(K_{m s}\right)$, as defined in this time-magnitude coordinate. Putting $t_{f}$ and $K_{m s}$ of the mainshock and $K_{p e}$ and $t$ of pre-events into equation (9), an accelerating seismic energy released curve $\left(\Sigma \sqrt{E_{j}}\right)$ for all pre-events and the mainshock is obtained. Finally, comes calculating rms of $\Sigma \sqrt{E_{j}}$ and assigning this value for each grid. The procedure is repeated until all grids are completed. The grids, that hold the predicted timeof-failure and the magnitude is the one that has a minimum value of rms of $\Sigma \sqrt{E_{j}}$. The isomaps of rms (rms $>10$ are not plotted) of $\Sigma \sqrt{E_{j}}$ for the largest 6 earthquakes among 40 mainshocks in Table-1 (marked with alphabetic from a to f) are illustrated in Figs. 5a, b, c, d, $\mathrm{e}, \mathrm{f}$, where horizontal and vertical axes are time-of-failure and magnitude, respectively. The black point marked the predicted time and magnitude that correspond to the grid with a minimum rms of $\Sigma \sqrt{E_{j}}$, while a star in each figure marks the true earthquake. The best prediction is in Fig. $5 \mathrm{c}$ for the 1983, $M_{\mathrm{L}}=5.8$ earthquake where the predicted value is almost the same as the true one. It is not perfect for the other five predictions, but they are in an acceptable rank. The predicted (solid lines) and true (dashed lines) energy acceleration curves of the above 6 mainshocks are displayed in Figs. 6a, b, c, d, e, f.

A similar procedure is used to predict the time-of-failure and magnitude for all 40 mainshocks listed in Table-1. The differences in magnitude and time-of-failure between predicted and true values for these 40 mainshocks are analyzed separately and displayed in Figs. 7 and 8, respectively. The magnitude difference shown in Fig. 7 reveals that the misfit is less than 1.2 with standard deviation 0.45 magnitude unit, and the time difference shown in Fig. 8 indicates that the misfit is less than 0.98 years with standard deviation 0.36 years, except for the $1994 M_{\mathrm{L}}=4.7$ earthquake that has a 3.32 year misfit. In general, those differences in magnitude and time-of-failure are sensible, which imply that the seismicity in central Taiwan gratify the energy acceleration model as well. 
(a)

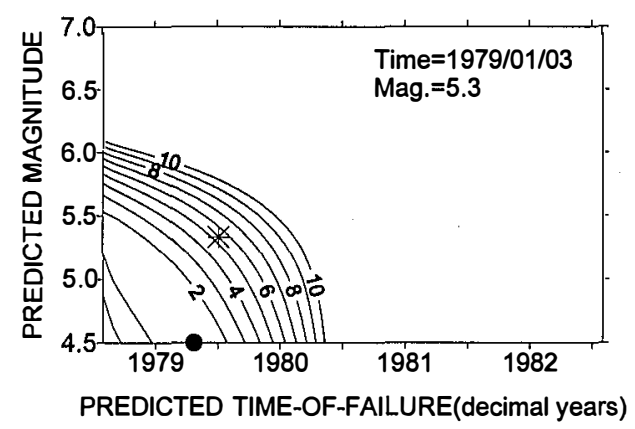

(c)

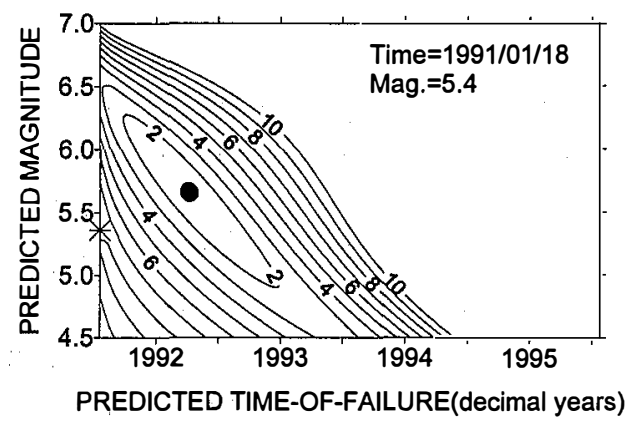

(e)

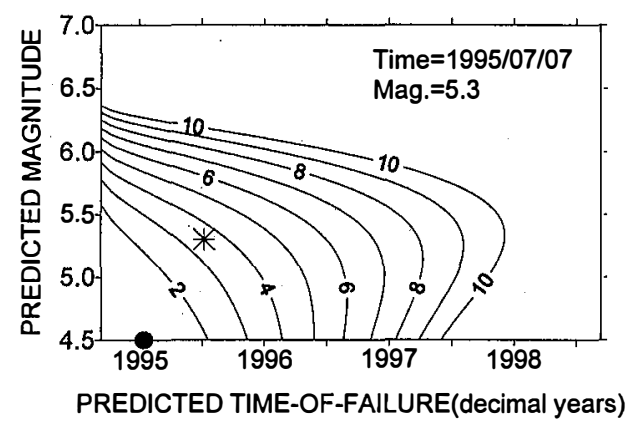

(b)

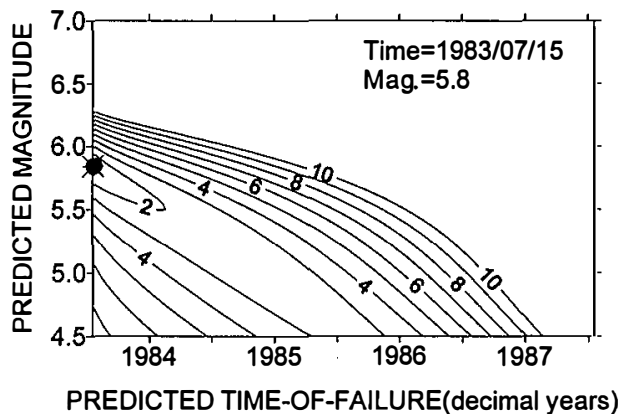

(d)

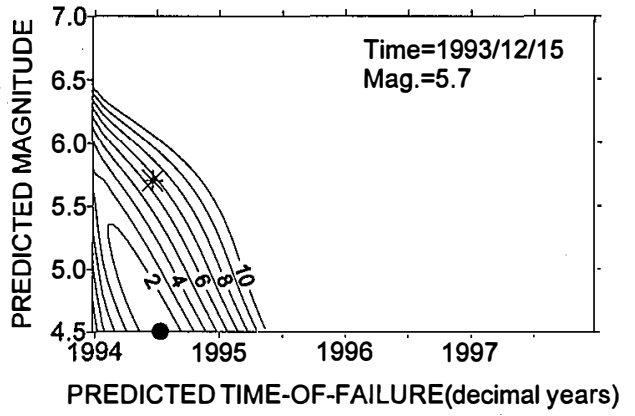

(f)

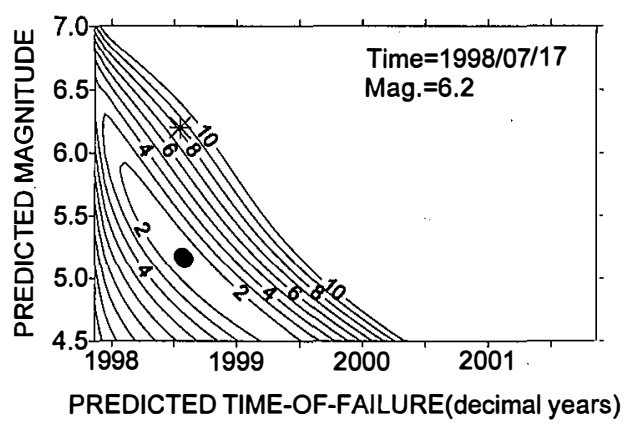

Fig. 5. Isomap of rms of $\Sigma \sqrt{E_{j}}$ for the largest 6 mainshocks marked with alphabetic letters from a to $\mathrm{f}$ in Table-1. The minimum rms of $\Sigma \sqrt{E_{j}}$ (marked by a black point in each Figure) correspond to the predicted time-offailure and magnitude while true mainshocks are marked by a star. Note that rms $>10$ are not plotted for better visualizations. 
(a)

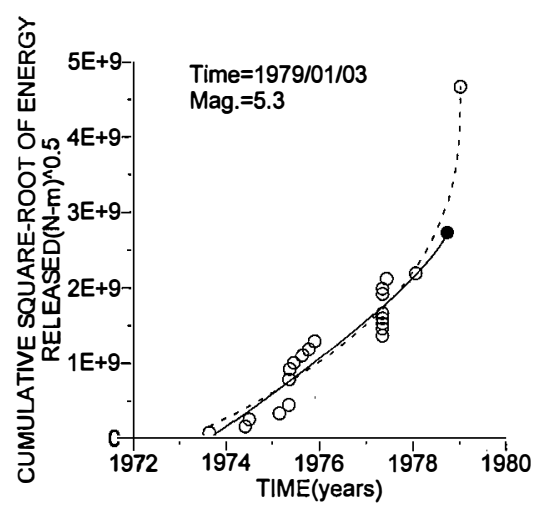

(c)

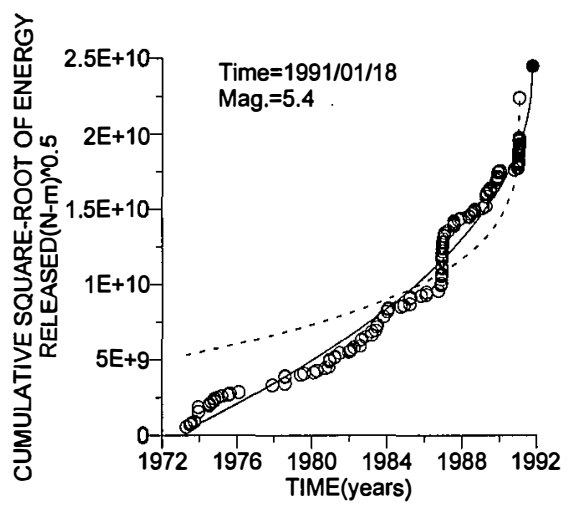

(e)

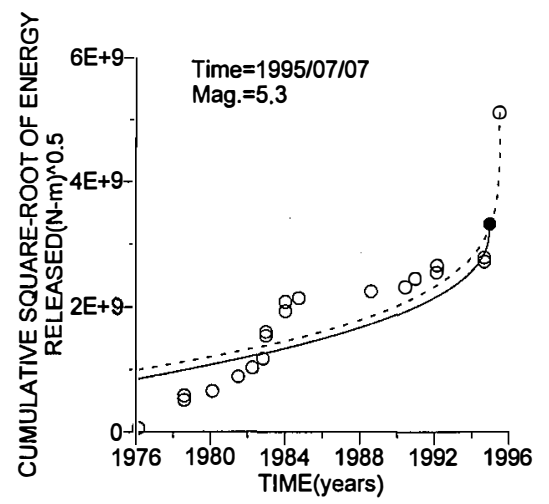

(b)

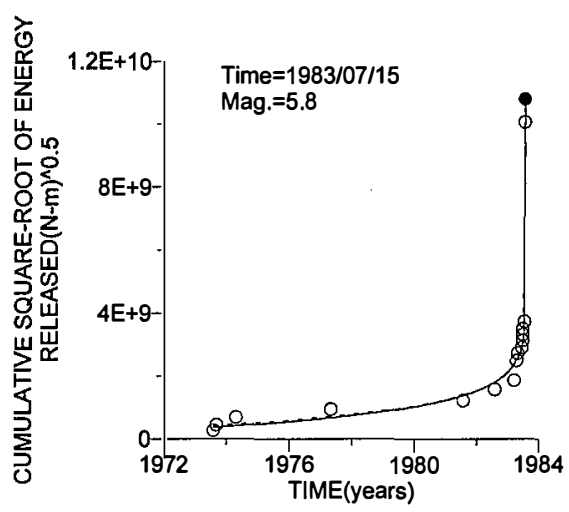

(d)

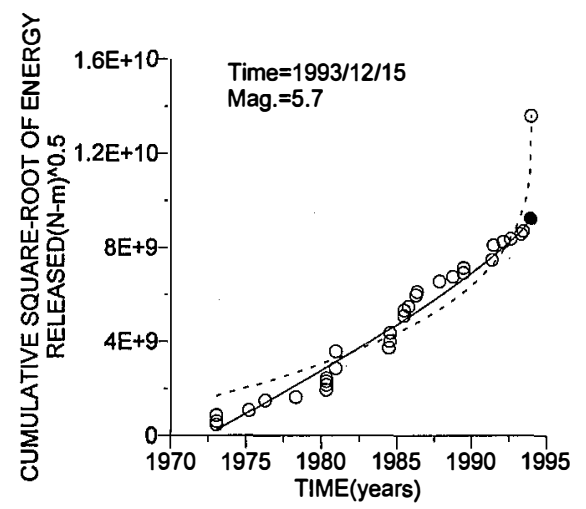

(f)

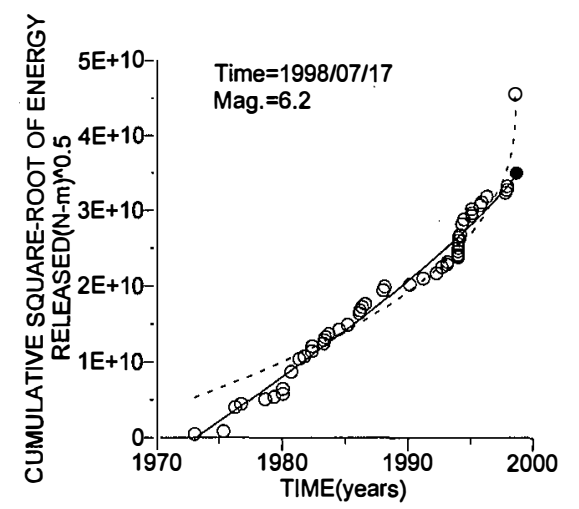

Fig. 6. Accelerating seismic energy release curves for the largest 6 mainshocks in Figs. 4a, b, c, d, f. 
Table 1

\begin{tabular}{|c|c|c|c|c|c|c|c|c|}
\hline & $\begin{array}{c}\text { Date } \\
\text { (YYMMDD) }\end{array}$ & $\begin{array}{c}\text { Time } \\
\text { (HHMMSS.SS) }\end{array}$ & $\begin{array}{l}\text { Lat. } \\
\left({ }^{\circ} \mathrm{N}\right)\end{array}$ & $\begin{array}{c}\text { Long. } \\
\left({ }^{\circ} \mathrm{E}\right)\end{array}$ & Mag. & $\begin{array}{c}\text { Search } \\
\text { Radius } \\
(\mathrm{km})\end{array}$ & $\begin{array}{c}\text { k-Values } \\
\left(\times 10^{6}\right) \\
\end{array}$ & m-Values \\
\hline \multirow[t]{7}{*}{$\mathrm{a}$} & 790103 & 063904.52 & 23.05 & 120.90 & 5.3 & 30.0 & 893.74 & 0.366 \\
\hline & 791101 & 123411.95 & 23.92 & 120.75 & 4.6 & 20.4 & 179.63 & 0.230 \\
\hline & 810330 & 222247.62 & 23.06 & 120.44 & 5.3 & 41.3 & 1817.43 & 0.322 \\
\hline & 811231 & 183841.61 & 23.19 & 120.37 & 4.7 & 10.8 & 345.02 & 0.336 \\
\hline & 820509 & 031051.37 & 23.58 & 120.89 & 4.6 & 11.6 & 403.05 & 0.256 \\
\hline & 820525 & 203758.51 & 23.53 & 120.50 & 4.6 & 10.3 & 154.72 & 0.225 \\
\hline & 830414 & 182540.50 & 23.02 & 120.95 & 4.6 & 5.5 & 37.87 & 0.046 \\
\hline \multirow[t]{12}{*}{ b } & 830715 & 103906.80 & 23.02 & 121.25 & 5.8 & 37.9 & 543.81 & 0.066 \\
\hline & 831025 & 112758.05 & 23.52 & 121.16 & 4.5 & 16.4 & 249.64 & 0.278 \\
\hline & 850219 & 204401.47 & 23.53 & 120.41 & 4.6 & 10.5 & 214.33 & 0.278 \\
\hline & 850403 & 103238.52 & 24.43 & 120.80 & 4.6 & 11.7 & 142.91 & 0.173 \\
\hline & 850730 & 143037.56 & 23.04 & 120.35 & 4.7 & 9.3 & 128.9 & 0.142 \\
\hline & 860128 & 061921.21 & 23.38 & 120.43 & 5.1 & 17.2 & 1433.05 & 0.518 \\
\hline & 860508 & 085907.88 & 23.97 & 121.10 & 5.1 & 11.0 & 775.12 & 0.347 \\
\hline & 871218 & 055340.85 & 23.38 & 120.78 & 5.2 & 7.6 & 182.76 & 0.076 \\
\hline & 890108 & 174140.31 & 24.08 & 120.33 & 5.2 & 57.9 & 1670.83 & 0.515 \\
\hline & 890201 & 195046.82 & 23.00 & 120.55 & 4.7 & 6.0 & 39.92 & 0.042 \\
\hline & 890411 & 180424.66 & 23.70 & 120.96 & 4.6 & 5.5 & 314.99 & 0.438 \\
\hline & 900522 & 113748.34 & 23.12 & 120.34 & 4.6 & 8.4 & 175.47 & 0.238 \\
\hline \multirow[t]{11}{*}{ c } & 910118 & 013627.01 & 23.68 & 121.27 & 5.4 & 36.7 & 2110.29 & 0.266 \\
\hline & 910224 & 133032.95 & 23.56 & 120.77 & 4.7 & 12.1 & 809.89 & 0.508 \\
\hline & 910309 & 221542.18 & 23.83 & 120.85 & 4.6 & 6.0 & 143.84 & 0.198 \\
\hline & 910317 & 043705.74 & 23.18 & 120.01 & 5.2 & 9.2 & 312.18 & 0.078 \\
\hline & 910623 & 180313.98 & 23.17 & 120.54 & 4.6 & 2.7 & 73.84 & 0.098 \\
\hline & 911224 & 025143.47 & 23.18 & 120.73 & 4.9 & 5.9 & 163.7 & 0.144 \\
\hline & 920324 & 050300.70 & 23.65 & 120.91 & 4.7 & 2.2 & 43.23 & 0.044 \\
\hline & 920528 & 204216.43 & 23.16 & 121.30 & 4.9 & 16.6 & 1031.58 & 0.527 \\
\hline & 920824 & 183734.97 & 23.56 & 120.68 & 4.7 & 5.2 & 258.84 & 0.351 \\
\hline & 930207 & 201950.75 & 24.26 & 120.78 & 4.6 & 3.1 & 74.22 & 0.095 \\
\hline & 930416 & 211012.43 & 23.16 & 120.82 & 4.9 & 5.3 & 207.63 & 0.115 \\
\hline \multirow[t]{4}{*}{ d } & 931215 & 214943.10 & 23.21 & 120.52 & 5.7 & 12.0 & 1435.81 & 0.302 \\
\hline & 940920 & 191618.18 & 23.13 & 120.98 & 4.7 & 2.7 & 176.48 & 0.720 \\
\hline & 941020 & 202626.23 & 23.14 & 120.93 & 4.5 & 3.5 & 170.4 & 0.121 \\
\hline & 950528 & 125536.07 & 23.10 & 121.27 & 4.6 & 3.0 & 47.07 & 0.052 \\
\hline \multirow[t]{5}{*}{ e } & 950707 & 030448.36 & 23.89 & 121.09 & 5.3 & 8.0 & 474.63 & 0.223 \\
\hline & 951031 & 222706.94 & 23.29 & 120.36 & 5.2 & 10.7 & 756.06 & 0.557 \\
\hline & 960407 & 165536.26 & 23.47 & 120.66 & 4.7 & 3.8 & 129.28 & 0.164 \\
\hline & 961009 & 092905.69 & 23.62 & 121.00 & 4.9 & 9.7 & 747.7 & 0.491 \\
\hline & 970704 & 183730.51 & 23.06 & 120.79 & 5.2 & 11.7 & 962.15 & 0.335 \\
\hline f & 980717 & 045114.96 & 23.50 & 120.66 & 6.2 & 35.6 & 4420.75 & 0.394 \\
\hline
\end{tabular}




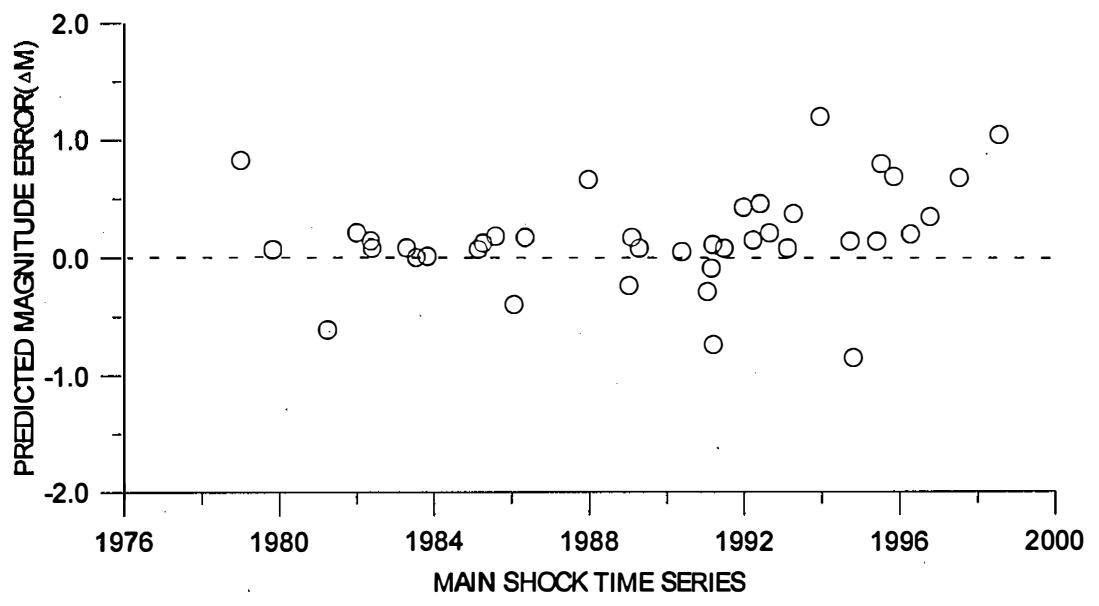

Fig. 7. Magnitude differences between predicted and true mainshock. The maximum difference is 1.2 unit in magnitude.

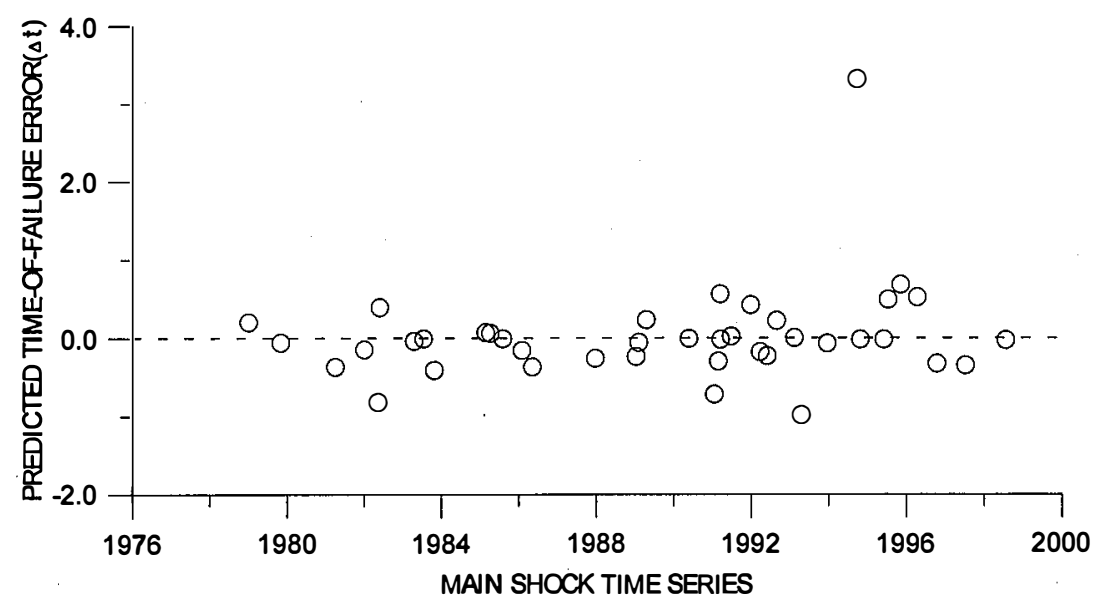

Fig. 8. Time differences between predicted and true time-of-failure. Although there is one with 3.32 years departure, the maximum difference is in a reasonable rank of 0.98 years. 


\section{DISCUSSIONS AND CONCLUSIONS}

An accelerating seismic energy release model was constructed on the basis of self-organized criticality, and then extended to the time-to-failure method for earthquake forecast using the pre-events of mainshock. Statistically vocalizations, the more pre-events the better model can be found, thus, at least 10 pre-events are needed for reliability. The second constraint is that the selected areas must have similar geological features such that their seismicities are comparable. The areas of central Taiwan chosen in this study, located in the continental plate, indeed satisfy this condition, and, thus, results of Figs. 7 and 8 are reasonable. Some of the selected pre-events were, but not necessarily located on the major fault where mainshock occurred. The reason this question might not be easy to answer is that the processes of earthquake nucleation and stress redistribution are far too complicated. However, based on the theory of seismic gap, very few earthquakes have been observed inside while many pre-shocks have been detected around the gap. To the contrary, the concept of characteristic earthquake implies that pre-shocks may occur on the major fault before critical point is reached. The third factor to be taken into account is the number and magnitude of mainshock. Based on magnitude-frequency distribution, Brehm and Braile $(1998,1999)$ chose different magnitude ranges for their investigation in the areas of New Madrid and southern California because the former has fewer earthquake activities than the later. To contain enough mainshocks, they choose magnitude of mainshock from 3.5 to 6.2 and from 5.5 to 7.3 for the areas of New Madrid and southern California, respectively. In this study, magnitude of 4.5 to 7.0 were selected in central Taiwan; however, this range must be justified when applying it to other areas of Taiwan where their magnitude-frequency distributions are different due to different geological conditions and seismicities.

In calculating unknown parameters of $k$ and $m$ (equation 1), Brehm and Braile (1999) used the nonlinear least-square method directly, while we separated it into two linear equations (4 and 5) and estimated them by applying linear-least square twice. An interesting result is that the estimated values of the constants $A$ and $B$ in equation (4) are very close to theirs [equation (14) in Brehm and Braile 1999], even though calculation procedure and investigation area are different.

According to the error analysis of Figs. 7, 8, the maximum predicted magnitude deviation is 1.2 units and time-of-failure is 0.98 years. Such departures are acceptable when considering intermediate-term earthquake forecasting. As a result, we may conclude that the seismicity of central Taiwan satisfies the accelerating seismic energy release model, which might be a useful tool for the future study of seismicity.

Acknowledgements An anonymous referee has provided constructive comments on parts of our discussions. The authors would like to express their gratitude to the Central Weather Bureau for providing available data. The National Science Council, R.O.C., under grant NSC 89-2921-M-194-001-EAF supported this research. 


\section{REFERENCES}

Brehm, D. J., and L. W. Braile, 1998: Intermediate-term earthquake prediction using precursory events the in New Madrid Seismic Zone. Bull. Seism. Soc. Am., 88, 564-580.

Brehm, D. J., and L. W. Braile, 1999: Intermediate-term earthquake prediction using the modified time-to-failure method in southern California. Bull. Seism. Soc. Am., 89, 275293.

Bufe, C. G., and D. J. Varnes, 1993: Predictive modeling of the seismic cycle of the Greater San Francisco Bay Region. J. Geophys. Res., 98, 9871-9883.

Bufe, C. G., S. P. Nishenko, and D. J. Varnes, 1994: Seismicity trends and potential for large earthquake in the Alaska-Aleutian region. Pageoph, 142, 83-99.

Das, S., and C. H. Scholz, 1981: Theory of time-dependent rupture in the earth. J. Geophys. Res., 86, 6039-6051.

Gardner, J. K., and L. Knopoff, 1974: Is the sequence of earthquakes in Southern California, with aftershocks removed, Poissonian? Bull. Seism. Soc. Am., 61, 1363-1367.

Jaume, S. C., and L. R. Sykes, 1999: Evolving towards a critical point : a review of accelerating seismic moment/energy prior to large and great earthquakes. Pageoph, 155, 279305.

Kanamori, H., 1977: The energy release in great earthquakes. J. Geophys. Res., 82, 60396051.

Kanamori, H., and D. L. Anderson, 1975: Theoretical basis of some empirical relationships in seismology. Bull. Seism. Soc. Am., 65, 1073-1095.

Varnes, D. J.,1989: Predicting earthquakes by analyzing acceleration precursory seismic activity. Pageoph, 130, 661-686.

Wang, J. H., 1992: Magnitude scales and their relations for Taiwan earthquakes : a review. TAO, 3, 449-468.

Wiemer, S., 2001: A software package to analyze seismicity: ZMAP. Seism. Res. Lett., 72, 374-383. 